\title{
ANÁLISIS DEL SISTEMA JURÍDICO ECUATORIANO PARA LA PREVENCIÓN Y SANCIÓN EFICAZ EN LA UTILIZACIÓN INDEBIDA DE INFORMACIÓN PRIVILEGIADA DE LOS MERCADOS DE VALORES
}

\section{ANALYSIS OF THE ECUADORIAN LEGAL SYSTEM FOR THE PREVENTION AND EFFECTIVE SANCTION OF THE IMPROPER USE OF INSIDE INFORMATION ON THE STOCK MARKETS}

\author{
César Bustamante Chong, Mgtr. \\ Magister en Administración de Empresas (Ecuador). \\ Docente de la Facultad de Ingenierías de la Universidad ECOTEC, Samborondón, Ecuador. \\ cbustamante@ecotec.edu.ec \\ Mariana Bustamante Chong, Mgtr. \\ Magister en Administración Pública (Ecuador). \\ Docente Investigadora de la Universidad Estatal del Sur de Manabí, Jipijapa, Ecuador. \\ mariana.bustamante@unesum.edu.ec
}

\section{ARTÍCULO DE REFLEXIÓN}

Recibido: 2 de diciembre de 2021

Aceptado: 2 de marzo de 2021

\section{RESUMEN}

El presente trabajo plantea el sistema jurídico ecuatoriano para la prevención y sanción eficaz en la utilización indebida de información privilegiada de los mercados de valores, centrado en examinar la situación actual del sistema jurídico ecuatoriano, e identificar factores internos y externos que afectan de alguna manera la gestión del sistema jurídico ecuatoriano en las organizaciones. La metodología adoptada es la exposición, análisis crítico y valorativo, los distintos problemas de interpretación que suscita la estructura del sistema jurídico ecuatoriano, la aplicación del principio de transparencia, es, consecuencia del rol protagónico exclusivamente de la información privilegiada, proporcionada por el insider trading, respecto de las actividades comerciales de uno o varios valores emitidos, no publicados al mercado, recapitulando todos los puntos de vista en las conclusiones generales que aparecerán al final del trabajo. Con los resultados obtenidos, se logró identificar cómo la logística del sistema jurídico ecuatoriano para la prevención y sanción eficaz en la utilización indebida de información privilegiada de los mercados de valores ha permitido que Ecuador, se consolide como un país guía para extender destrezas de recompensas entre las sistematizaciones del mercado financiero, y sus mecanismos en el mercado de valores. 
Palabras clave: sistema jurídico ecuatoriano, insider trading, información privilegiada, mercado de valores

\section{ABSTRACT}

This paper raises the Ecuadorian legal system for the prevention and effective punishment of the misuse of privileged information in the securities markets, focused on examining the current situation of the Ecuadorian legal system, and identifying internal and external factors that affect in some way the management of the Ecuadorian legal system in organizations. The methodology adopted is the exposition, critical and evaluative analysis, the different interpretation problems that the structure of the Ecuadorian legal system raises, the application of the principle of transparency, is a consequence of the leading role exclusively of the privileged information, provided by the insider trading, regarding the commercial activities of one or more securities issued, not published to the market, recapitulating all points of view in the general conclusions that will appear at the end of the work. With the results obtained, it was possible to identify how the logistics of the Ecuadorian legal system for the prevention and effective sanction in the misuse of privileged information on the stock markets has allowed Ecuador to consolidate itself as a guide country to extend rewards skills among the systematization of the financial market, and its mechanisms in the stock market.

Keywords: ecuadorian legal system, insider trading, privileged information, stock market

\section{INTRODUCCIÓN}

El insider trading, como se lo conoce en el derecho angloamericano o en el derecho francés como delito de iniciados, y la imagen del uso de información privilegiada en el mercado de valores, se ha instituido últimamente en la ley de Mercado de Valores del Ecuador, a pesar de que, existían hace algunos años atrás sanciones penales en países vecinos y europeos, para este tipo de prácticas, que vulneran substancialmente, el adecuado ejercicio del mercado de valores, sin embargo Ecuador, todavía no lo establece como contravención en su régimen penal, estableciendo estrictamente reglamentos administrativos a través de la Ley de Mercado de Valores (LMV) (Vega, 2010). El procedimiento norteamericano es la base de aquellas legislaciones que se han depurado por la limitación de las sistematizaciones de iniciados, aunque conforme a cada sistema correccional ha organizado la contravención en función de medidas a veces poco concurrentes con el sistema americano, v.gr., el creciente abandono del enfoque societario, del fenómeno en el valor del bien jurídico protegido (p.21), siendo el fenómeno del insider trading la médula de una mayor experiencia organizadora en el sistema americano, ya 35 
que en el recordado crack de la bolsa de Nueva York (1929), los implicados en el mismo se vieron condicionados a confirmar las rutas para las leyes de valores con el propósito de evadir ciertas prácticas fraudulentas.

Redimiendo algunas expresiones de Vega (2010), en el caso de nuestra legislación bursátil, que se refieren a puras sanciones administrativas, no se ha podido considerar como "figura delictiva" no obstante el "legislador español incriminó penalmente las operaciones de iniciados", la legislación penal española en el transcurso de su reforma, siempre discurrió como delito el abuso de información privilegiada: y en consecuencia, ha expuesto sanciones realmente enérgicas, y renovadoras.

Se acaba de aprobar dos normas, de parte de la Asamblea Nacional del Ecuador, la primera se refiere al Código Orgánico Integral Penal, y la segunda al Proyecto de Ley Orgánica para el Fortalecimiento y Optimización del Sector Societario y Bursátil.

En cuanto a la primera, en el momento de aplicarla resulta imprecisa, y general en lo pertinente a la clase de información a la que se refiere, demitiendo un problema de interpretación que provienen de su confusa estructura típica, se espera errar y que su aplicación sea eficaz, puesto que, actualmente, se desconoce que estos criterios den resultado en algún caso, en cuanto en la LMV, no ocurría, puesto que la autoridad pública se valía directamente en la dimensión del perjuicio, dimitiendo en la ilegalidad algunos asuntos o actuando en otros de manera injusta.

La segunda norma, básicamente hace referencia al incremento de la dureza de las sanciones tanto en multas, cambiando de dólares a salarios básico unificados, como también en sanciones administrativas o disciplinarias, no se verifica practica alguna que transforme o remplace las ya determinadas en la LMV, en cuanto a la información privilegiada, a excepción del artículo 78 del proyecto de ley que sustituye el artículo 208 de la LMV.

La información privilegiada que tiene el insider trading, individuo que asume dicha información de este mercado, posee la obligación jurídica de no difundir públicamente e ilícitamente esta información con relación a los valores y las utilidades alcanzadas.

Considerando que, la eficiencia del mercado de valores como su objetivo principal, y su repercusión en el incremento de la confianza del inversor, fundamentado en el Principio de Transparencia como la base que rigen los mercados, dependerá del análisis que permiten a los inversionistas, tener la evidencia, de estar instruidos de los riesgos que asumen, para finalmente tomar sus propias decisiones, a través del previo estudio de la investigación útil en el mercado, con dependencia al ejercicio que procuren ejecutar. 
Por lo tanto, la afectación a la transparencia de las negociaciones del mercado de valores, se deben al uso indebido de la información del insider trading, obteniendo un clima de desconfianza e inseguridad entre los emisores, inversionistas, intermediarios, y en general entre los operadores y colaboradores del mercado (Hartman, 2014). El insider trading en la ejecución de acciones de compra y venta de una inversión, refiriéndose a su obra sobre la ética en los negocios, incumple toda correlación de responsabilidad y confianza, en el instante en el que se coloca información notable sobre la inversión inmersa que, no está expuesta al resto de agentes que intervienen en el mercado.

La evolución tecnológica ha traído cambios constantes en todas los ámbitos del conocimiento, revolucionando a la sociedad entera, convirtiéndola en un ente informatizado a cabalidad, dando resultados positivos en la ciencia y tecnología; conjuntamente con dicho mejoramiento, también la aparición de nuevos acontecimientos relacionados con formas delictivas asociadas a estas herramientas tecnológicas, lo que ha autorizado que los delincuentes tradicionales empleen nuevos modus operandi en el cometimiento de sus fechorías, tal es así que los delitos informáticos en el mundo entero se han transformado en los mecanismos más aptos y modernos para la agresión a bienes jurídicos protegidos, y nuestro país no es la excepción.

De ahí entonces que forzosamente más que nunca que el Lus Puniendi o poder sancionador del Estado se aplique y se encuentre en constante actualización, de tal manera que, los ilícitos cometidos diariamente, hallen un asidero jurídico coercitivo eficiente y efectivo. Por lo que, en el caso ecuatoriano, resulta sui géneris, que concurran tipos penales referentes a los delitos informáticos, más sin embargo que, la aplicabilidad de dichas normas en la vida práctica, resulten verdaderamente difíciles de cumplir, esto debido a los problemas que producen la internacionalización de dichos ilícitos, en aspectos precisos como los de la jurisdicción y la competencia.

La digitalización de la información ha revolucionado al mundo entero, desarrollando las posibilidades comunicacionales y eliminando las barreras físicas y temporales entre los beneficiarios de las herramientas informáticas, facilitando el proceso dinámico de la globalización entre los diferentes Estados, quienes se ven beneficiados por aquel avance tecnológico.

Sin embargo, paradójicamente indudablemente tal progreso ha organizado uno de los peligros más importantes dentro del mundo digital, poniendo en riesgo a bienes jurídicos protegidos por la mayoría de legislaciones mundiales, muchas de las cuales se ven desactualizadas ante el 
extraordinario desarrollo de la ciencia y tecnología que estimula a sus usuarios a localizar novedosas y atrayentes modalidades de delinquir a través de los medios telemáticos.

De ahí que en el Ecuador, como en otros países, tiene como efecto el hecho de que si bien algunas conductas delictuosas se encuentran reprimidas penalmente, la mayor parte de ellas no reciben una sanción efectiva, dada la particularidad de la transnacionalidad de la que gozan los delitos informáticos, los que consiguen adoptar las más complejas formas delictivas, reduciendo o incluso borrando por completo, vestigio alguno de su accionar, por lo que deriva en hacer realmente compleja la tarea del poder judicial al sancionar tales conductas.

En el presente artículo se detalla primero un acercamiento a la situación objeto de estudio, todo esto con el fin de detallar la importancia que tiene la investigación en el análisis del sistema jurídico ecuatoriano para la prevención y sanción eficaz en la utilización indebida de información privilegiada de los mercados de valores.

En la segunda parte todo lo concerniente a conceptos básicos y primordiales que permiten obtener los fundamentos y bases necesarias, que describe la importancia, objetivos, componentes y herramientas útiles para la comprensión y el desarrollo del sistema jurídico ecuatoriano, detallándose el diagnóstico situacional de dicho proceso en la prevención y sanción eficaz en la utilización indebida de información privilegiada de los mercados de valores objeto de estudio, en el cual se utilizó método deductivo, con el fin de obtener información relevante y coherente que, sirvió de base para fundamentar las conclusiones de los hechos observados en los diferentes entornos correspondientes a las variables investigadas.

El Objetivo del presente trabajo es: analizar los trascendentales conceptos, orígenes y evolución del sistema jurídico ecuatoriano para la prevención y sanción eficaz en el uso indebido de información privilegiada en el mercado de valores.

\section{REVISIÓN TEÓRICA}

\section{Sustento jurídico para las reformas legales: Análisis de la Ley de Mercado de Valores.}

Previo analizar la Ley de Mercado de Valores del Ecuador, se detallan algunos documentos que fueron antecedentes para la codificación de la Ley de 1993 y de 1998. Al respecto, conforme a un estudio de la Superintendencia de Compañías del año 1984, la legislación específica del mercado de valores vigente a esa fecha, estaba constituida fundamentalmente por los siguientes documentos. (Ecuador, 1984 ) (La Ley No 111, de febrero 26 de 1969 de la Comisión Legislativa permanente, Promulgada en el R.O. No. 144, el 26 de marzo del 1969), la cual faculta el establecimiento de Bolsas de Valores en el país; (El decreto ejecutivo No. 1182, de mayo 30 de 
1969, Promulgada en el R.O. No. 216, el 07 de julio del 1969) Por el cual se autorizó la creación de las Bolsas de Valores de Quito y Guayaquil; Los Estatutos Sociales de las Bolsas de Valores de Quito y Guayaquil, protocolizados por escritura pública de agosto 4 de 1969 y septiembre 2 del mismo año; (Los Reglamentos para el funcionamiento de las Bolsas de Valores de Quito y Guayaquil; Dictados por la Superintendencia de Compañías mediante Resoluciones No. 905 y 907, respectivamente, de noviembre 24 de 1969); La Ley de Compañías, en cuanto contiene las normas referentes a la sociedad anónima, así como algunas disposiciones de carácter tributario; y, La Constitución de la Republica, la Ley de Régimen Monetario, la Ley de Impuesto a la Renta, la Ley General de Bancos y otras.

La Ley de Mercado de Valores del año de 1993, como es obvio empezó como una propuesta de nueva legislación sobre el mercado de valores. A modo de antecedente, al respecto el estudio de la Superintendencia de Compañías del año de 1984 (El Mercado de Valores en el Ecuador., 1984) lo cuenta en los siguientes términos:

En ejecución del Programa Integral para el Desarrollo del Mercado de Valores del Ecuador, que está llevando a cabo la Superintendencia de Compañías, se ha elaborado dos anteproyectos de Ley que, en opinión de esta entidad, se consideran indispensables para establecer un mercado de valores ágil y moderno.

Ellos son el Anteproyecto de Ley de Mercado de Valores y el Anteproyecto de Ley de Compañías y Fondos de Inversión. El anteproyecto de la Ley de Mercado de Valores de 1993 (Ibidem), resume algunos problemas por los cuales se creó la misma, por ejemplo, el mercado de valores no era muy utilizado, dado los demasiados impuestos que tenían que pagar las partes, desconfianza de los potenciales inversionistas, falta de información oportuna, objetiva y completa sobre las compañías, de los valores emitidos y el funcionamiento del mercado; entre otros.

Estos anteproyectos comenzaron a ser redactados "en 1981 que pese a los esfuerzos emprendidos no tuvieron acogida; no fue sino hasta que el 1993 que el Proyecto de Ley auspiciado por la Superintendencia de Compañías fue presentado al Congreso Nacional, que lo aprobó el 7 mayo de 1993, y fue publicado en el Registro Oficial No. 199 del 28 del mismo mes y año". (Garzón Viteri, 2008)

La creación de la ley, fue vital para el crecimiento del mercado y de la inversión privada. En cumplimiento de sus disposiciones, "se introdujeron importantes cambios orientados a la modernización de los instrumentos e instituciones que tenían como finalidad el coadyuvar a la 
canalización del ahorro hacia la inversión en valores negociables". (Garzón Viteri, El Mercado de Valores y los Derivados Financieros. Su Enfoque Jurídico. (Tesina de Grado), 2008)

\section{Sistema jurídico ecuatoriano: Constitucional}

El creciente progreso de la ciencia y tecnología exige al campo jurídico a conservar una firma adhesión y modernización a las innovaciones procedentes de la sociedad, fundamentalmente en lo relativo al manejo del internet, herramienta que en el presente se ha tornado necesario, sin diferencia alguna entre los individuos de la sociedad, mismo que si no se lo maneja correctamente, puede ser la causa de diferentes delitos realizados culposa y dolosamente, de ahí que sea preciso instaurar normas jurídicas efectivas que permitan lograr los fines del ordenamiento penal, siendo éstos los pertenecientes a la sanción punitiva correspondiente, la rehabilitación y reinserción social del sujeto activo de la infracción y por otra parte, la reparación integral de la víctima de tales delitos.

Por otro lado, la certeza de la norma penal, no sólo consentirá a los comprometidos en el proceso penal, recibir lo que cada uno de ellos merece, sino también a toda la sociedad ecuatoriana y regional, pues se conservará mayor certidumbre y seguridad al hacer uso de las herramientas informáticas, tan indispensables en el diario vivir.

El resultado del surgimiento de las herramientas tecnológicas en la sociedad desde comienzos del año de 1960 se ha transformado en un indudable hito histórico, pues la modernidad ha logrado nuevas formas delictivas, a propósito de los aspectos positivos del aparecimiento de tales herramientas. De ahí entonces, que las diferentes legislaciones penales a nivel mundial, se han preocupado por modernizar y crear nuevos tipos penales conforme con la realidad circundante.

El caso del Estado Ecuatoriano, no ha sido la excepción, puesto que, a partir del 10 de agosto de 2014, entró en vigencia el innovador Código Orgánico Integral Penal, que debía ajustarse necesariamente a la moderna Constitución de la República de 2008, que traía consigo un conjunto de nuevos derechos y garantías, que debían regir en todo el ordenamiento jurídico vigente, incluido el campo penal.

Ahora bien, es indudable que tal como el progreso tecnológico ha logrado incontables beneficios a la entera sociedad al utilizar los medios informáticos de un modo adecuado, también los perjuicios ocasionados por la incorrecta utilización de éstos, han llegado a ser cuantiosos, puesto que se han enfocado a la destrucción de bienes jurídicos protegidos como el de la 
información o integridad, pese a los grandes esfuerzos legislativos por establecer normas jurídicas que regulen tales conductas.

En tal virtud, mediante la caracterización de nuevas contraversiones lo que se busca es que el poder sancionador estatal trascienda incluso esferas intangibles por la mano humana, pues ese es la exigencia que la actual sociedad le reclama al Estado, fundamentalmente aquella que no ha tenido ninguna formación en lo relativo a esta nuevas formas delictivas y que sin el mayor cuidado acceden a fuentes tecnológicas que forman parte de la vida diaria de las personas, pero que en la actualidad se constituyen en potenciales medios delictivos, y por tanto, en enemigos de la seguridad personal.

Por tanto, pese a existir legislación penal referente a los delitos informáticos en el Ecuador, el problema real procede de la problemática que tienen las autoridades con el fin de detener tal mafia informática a nivel mundial, puesto que tales delitos provienen de fronteras extranjeras que por un lado, en muchos casos presumen verdaderos retos investigativos para las autoridades, y por otro, crean percepciones de impunidad y desconfianza en la psiquis de aquellos sujetos pasivos de las infracciones, por el hecho de que éstos ilícitos no se pueden sancionar efectivamente y por tanto generan inseguridad jurídica.

El sistema jurídico ecuatoriano, en la prevención y sanción eficaz en la utilización indebida de información privilegiada de los mercados de valores, se fundamenta en, la vigente Constitución de la República de 2008, quien se encarga de esgrimir nuevos derechos o atribuciones para los habitantes del territorio ecuatoriano, garantizando su efectivo cumplimiento mediante diversos mecanismos, en los que se demanda a la autoridad el pleno goce de los mismos; más aún, cuando de acuerdo al espíritu innovador neoconstitucional que pregona la Carta Fundamental, el Estado se constituye para que los derechos en ella enunciados, sean efectiva y realmente ejercidos por los individuos y colectividades.

Por lo que se busca que se cubra el requerimiento de justicia exigido por los mandantes, en los diversos ámbitos del quehacer social, dentro del cual inevitablemente debemos referirnos al aspecto tecnológico, que se ha convertido en una arista fundamental dentro del desarrollo ecuatoriano, y que también se ha visto gravemente perjudicado por la mafia delincuencial, situación que es el factor común que comparte Ecuador con el resto de países del mundo, especialmente con aquellos en donde la legislación penal nacional es menos rigurosa para tales infracciones. 
En el caso concreto ecuatoriano, tenemos pues, una Constitución ajustada a las necesidades circundantes del medio, es así que en el artículo 11 numeral 3, se establece que: "los derechos y garantías establecidos en la Constitución y en los instrumentos internacionales de derechos humanos serán de directa e inmediata aplicación por y ante cualquier servidora o servidor público, administrativo o judicial" y en el numeral 8, se menciona: "el contenido de los derechos se desarrollará de manera progresiva a través de las normas, la jurisprudencia, y las políticas públicas". De lo anterior citado, se colige por tanto que, la normativa constitucional y legal se irá adecuando a los nuevos paradigmas que afronte el Estado ecuatoriano, pues uno de los principios constitucionales, extraídos de los artículos citados, es el de progresividad, el mismo que entraña que el Ecuador tiene la obligación de generar o crear oportunamente una mayor cobertura y mejor protección a los derechos del ciudadano, de modo que la evolución normativa sea constante y se encuentre conforme con la dialéctica social, restringiendo en todo momento el retroceso de la legislación en perjuicio de los derechos.

Ahora bien, en el artículo 18 de la Constitución, se garantiza el acceso libre a la información, a todas las personas en forma individual o colectiva, y siendo el bien jurídico protegido en los delitos informáticos la información precisamente, este articulado es de especial importancia en el desarrollo del presente trabajo investigativo; ya que si bien es cierto, esta prerrogativa permite al ciudadano hacer uso de la información en todo momento, no le está concedido mal usarla en el cometimiento de delitos que atenten contra ésta, tomando en consideración la repercusión que tal situación acarrea al sujeto pasivo de la infracción.

Concordantemente, en el artículo 66 numeral 19 se establece que los datos de carácter personal serán protegidos y que se requerirá la previa autorización del titular para su uso en manos de terceros. En este sentido, en el numeral 21 del mismo artículo se garantiza el derecho a la inviolabilidad de la correspondencia física y virtual, pues se tiene conciencia del grado de afectación que puede sufrir la información en manos de sujetos no adecuados.

Precisamente, uno de los derechos afectados al vulnerar la información ajena, es el referente a la intimidad personal y familiar constante en el referido artículo 66 numeral 20, pues éste es un derecho personalísimo, innato a la propia naturaleza propia del ser humano, ya que implica el designio personal de mantener en reserva asuntos privados, en los cuales no se desea que absolutamente nadie intervenga, de ahí que éste sea catalogado también como "el derecho a estar solo", por lo que en el caso de que se mal utilice la información, se estaría atentando seriamente contra ésta prerrogativa constitucional. 


\section{Información Privilegiada}

\section{Definiciones de información privilegiada}

El uso indebido o abuso de información privilegiada en el mercado de valores, se ha constituido en un problema en el mercado de valores, reside en la posición de una información fundamental que los demás no conocen, es decir; que no ha sido concebida como pública y que acede a dicha información al que la posee, anticipándose al posible progreso de las cotizaciones y aplicar con ventaja frente al resto del público que interviene en el mercado de valores, favoreciendo a unos pocos inversionistas que corresponden a la empresa.

Este prototipo de procedimiento, que se da internamente del mercado de valores, desde quien crea la información se percibir, estableciéndose en una competencia desleal por la trascendencia inmediata de sus potenciales favorecidos, que forjaron la información fundamental, como directores, socios mayoritarios, gerentes, asistentes, secretarios y afectando a muchos inversionistas que están fuera de la empresa y que no tienen conocimiento de dicha información valiosa.

La palabra insider trading tiene su origen anglosajón o insider dealing según denominación británica. Buscando en la web una versión a estos términos, cierta persona que estaba aplicando para trabajar en Dominos Pizza, preguntaba que representa trabajar de insider u outsider, en relación a esto le respondieron que los referentes procesos, simbolizan trabajar dentro o fuera de Dóminos Pizza. Insider. "Persona que corresponde a una organización especifica o que esta direccionada a información confidencial" (Press, 2003). "Persona con información confidencial íntimamente en una organización" (LAROUSSE).

Se concreta la ineficaz ampliación al plazo de suspensión de la autorización de funcionamiento establecido por el reglamento de sanciones de la Ley. Esto criterio y propuesta se ha realizado teniendo en cuenta el derecho comparado, esto es, el Reglamento de los Mecanismos Centralizados de Negociación para valores de deuda pública e instrumentos derivados de éstos, del Mercado Integrado Latinoamericano MILA (Peru., 2014). Es necesario entender que el mercado de valores peruano, permite sistemas de Intermediación Directa e Indirecta, es así que el procedimiento directo, igualmente distinguido como desintermediación financiera o de mercado de valores, posee como característica que el dueño de excedentes en efectivo, es quien resuelve dónde y cuándo situar su dinero, tomando a cambio un título valor, equivalente al valor mobiliario; equivalente al uso del valor específico de retribuciones de intervención y como valor especifico de deuda. 
Y en relación al sistema de intermediación indirecto, este se localiza en la banca comercial, adonde el público ahorrista cancela su dinero a cambio de libreta de ahorros, un certificado de depósito u otro documento que obliga a la banca o financiera a devolver el dinero al ahorrista en cuanto éste lo solicite. Luego, la referida empresa del sistema financiero decide ¿Qué hacer, como cobrar, donde invertirá quien prestar, que proyectos instruir, que aval requerir en garantía y demás contenidos con el dinero? (Torres, 2002).

\section{Antecedentes del mercado de valores en Ecuador}

Después de casi 30 años en el año 1935, mediante decretos ejecutivos se instituyera en la ciudad de Guayaquil la mencionada "Bolsa de Valores y Productos del Ecuador C. A.", en el Código de Comercio de 1906, que contenía algunas prácticas en materia de bolsas y agentes de comercio, se ubicaron los primeros antecedentes del mercado de valores en el Ecuador. (Rumazo Arcos, 1990).

Las acciones de la Empresa Eléctrica del Ecuador y de la Compañía Nacional de Teléfonos, Bonos de la Deuda Pública Interna, Cedulas Hipotecarias y también productos tales como arroz, azúcar, café, cacao, algodón y otros, se cotizaron en el primer mercado de valores y productos que fue fundado con la finalidad de promover el desarrollo del mercado de valores.

(El Diagnostico del Mercado de Valores en el Ecuador, 1990, pág. 27). Desde mayo de 1935 a junio de 1936, fue el periodo corto que duro esta institución, la principal causa fue entre otros factores la deficiente oferta de títulos valores, la disminución de la capacidad de ahorro en el país en esa época, la insuficiente educación del público en este prototipo de inversiones financieras, la primitiva estructura industrial del país y las alteraciones de orden político ajustadas a esa época.

El Fondo de Regulación de Valores (Rumazo Arcos, 1990), funcionaba como representación del Banco Central, creada con el fin de moderar el mercado de bonos del Estado, limitada pero importante, primero y de la Comisión de Valores, después. (Ibidem, pág. 27)

Mediante el Decreto despachado en mayo de 1953, se extendieron las funciones de este Fondo, autorizándolo para comerciar con cedulas hipotecarias formuladas por el Banco Nacional de Fomento y los bancos privados, con desenlaces de fomento agrícola e industrial. Posteriormente se independizo al Fondo del Banco Central, convirtiéndose en una entidad autónoma. En el año 1955 se fundó sustituyéndolo la Comisión Nacional de Valores, a la cual se le concedió la función concreta de comprar y vender tanto bonos del Estado como cedulas hipotecarias. 
(“El Diagnostico del Mercado de Valores en el Ecuador.” (1969. D. -L., 1969). Hasta mediados del año de 1964, esta comisión trabajó, en que se transformó en Comisión de Valores Corporación Financiera Nacional. La finalidad de este nuevo acontecimiento no solo fue incrementar y regular el mercado de valores, sino, otorgar créditos y promocionar empresas mediante la aportación de capitales. Fue esta institución, la que tomo la iniciativa de incitar la creación de las bolsas de valores en el Ecuador, y que se vio concretado mediante emisión de Decreto No. 111 expedido el 26 de febrero de 1969., pág. 28, que autoriza al presidente de la Republica, el establecimiento de Bolsas de Valores, dependiente del control de la Superintendencia de Compañías. Efectuando cumplimiento con lo establecido en el referido Decreto, fue que mediante(1969.)

Las dos Bolsas de Valores emprendieron sus operaciones casi paralelamente en el año de 1970. La Bolsa de Quito inauguro sus labores el 10 de agosto y la Bolsa de Valores de Guayaquil empezó sus labores el 1 de septiembre, estableciéndose de este modo el mercado de valores en el Ecuador.

\section{Mercado de valores en Ecuador}

En Roma los comerciantes se reunían de forma habitual a una hora fija a comprar y vender conocido como el collegiummercatorum, en Atenas existía lo que se conocía como emporion, en el que según (Salazar, 2014), los mercados de valores existen desde la antigüedad.

Actualmente como consecuencia del importante desarrollo industrial y comercial, se provocó una ampliación en la transacción bursátil de valores, fusionado a la adecuada evolución del sistema de economía capitalista, sin embargo, los actuales mercados de valores proceden de las ciudades comerciales italianas y holandesas del siglo XIII, por tanto, el primer mercado de valores moderno fue en la ciudad holandesa de Amberes, creado en el año 1531. En el transcurso del siglo XVI iniciaron la expansión de mercados en toda Europa, en Toulouse (1549), o Londres (1571); teniendo como consecuencia el establecimiento de las de Ámsterdam, Hamburgo y París.

El incremento de la producción y las comunicaciones, los mediadores emprendieron el importante papel en los mercados. En el transcurso de la década de los 60, los países en vías de desarrollo disminuyeron su intervención a constituir parte del comercio mundial, debido a que el mercado mundial estaba compuesto en su mayor parte de exportaciones de productos procedentes de las zonas industriales, que se manifestaban en la estructura del comercio mundial. En la década de los 70 , se originan trascendentales reformas que establecen una diversificación en la estructura del mercado mundial, exclusivamente en lo que corresponde a los 
productos primarios, ratificándose el empoderamiento de artículos manufacturados, que se mantuvieron en ascenso constante.

\section{Diagnostico situacional del mercado de valores.}

En lo que va de la última década, la situación presente de los mercados de valores tiene problemas de tipo coyuntural y estructural. El mercado de valores del Ecuador no es la excepción de estas insuficiencias, concretamente en lo que interviene la competencia bancaria y bursátil y escasa cultura bursátil.

Se observa, como algo perjudicial que en lo que va de la última década, un crecimiento deficiente en el mercado de valores y el cual a su vez, se puede atribuirse a que a este tipo de inconvenientes concurren otros concernientes al desconocimiento del mercado de valores en lo que tiene que ver al funcionamiento y las prioridades existentes en el manejo de sus mecanismos, dado que en su momento por largo tiempo ha sido manipulado para unos pocos instruidos en la materia, principalmente el sistema bancario, que supo producir muy bien la falta de cultura bursátil en las personas, para la promoción de sus intereses, trayendo como consecuencia un improcedente direccionamiento y administración de la información dentro de este campo.

Situación que al parecer muestran problemas de tipo coyuntural, que están agrupadas con la presencia de la inseguridad jurídica, la postura de políticas macroeconómicas, tributarias, fiscales y financieras trae como consecuencia la desactivación a la inversión externa en el país, además, las crisis financieras, volatilidad en los mercados financieros internacionales, diversificación en las tasas de interés; y los de tipo estructural, que se describen con la clasificación del mercado donde se verifican las operaciones, por ejemplo: la rivalidad de la actividad bancaria con la actividad bursátil y la cultura bursátil insuficiente.

En el caso del Mercado de Valores ecuatoriano se imputa que es joven; contexto que en la actualidad se encuentra inmerso en los problemas mencionados a nivel latinoamericano, debido especialmente a que el país no brinda perspectivas interesantes de inversión, políticas macroeconómicas que garanticen las características de cambios reales, inseguridad jurídica, los impuestos, interferencias de los bancos y sobre todo la escasa cultura bursátil dentro del país.

A estas dificultades se agregan otros que están agrupados, personas que tienen capitales exuberantes y que se cristalizan en ahorros, pues los bancos han canalizado la información, de tal forma que sean ellos los únicos receptores de dichos recursos, evitando así, que estos recursos excedentes sean invertidos en el mercado de valores. 
De igual manera, se puede atribuirse que a este tipo de inconvenientes está presentes otros relacionados como el desconocimiento del mercado de valores en lo que tiene que ver la labor y las ventajas en la utilización de sus componentes, dado que ha estado por mucho tiempo reservado para unos pocos involucrados en la materia, principalmente el sistema bancario, que supo producir muy bien con la falta de cultura bursátil en las personas, para el lanzamiento de sus intereses.

En el mercado de valores nacional, según una investigación realizada por (Méndez Prado, 2016) nos indica que la explicación por la cual el mercado de valores ecuatoriano no se ha desarrollado como sus símiles suramericanos es por: idiosincrasia, intereses creados desde las organizaciones involucradas en el mercado, alto margen de empresas familiares cerradas, oferta limitada de productos para el pequeño y mediano inversionista, costo de operaciones muy alto, escasa cultura bursátil y una información insuficiente, poco amigable y sobre todo desactualizada.

Sin embargo, también no debemos menospreciar a las empresas públicas con economía mixta que según (Hablich Sánchez, Taola Rocuano, \& Agila Maldonado, 2018) bajo la premisa de que los mercados de valores ecuatorianos deberán desarrollar estrategias para su participación, las mismas todavía no pueden tener una variable de confianza que sostenga la responsabilidad que implica la inversión del capital mixto de una empresa pública en un mercado de valores con muchas debilidades mostradas, puesto que es el estado que maneja la economía del país y no puede dar un uso irresponsable de sus bienes, porque acarrearía la quiebra de la economía y consecuencias sociales desastrosas.

\section{MATERIALES Y MÉTODOS}

En la presente investigación se realizará la aplicación de métodos de carácter lógico, que ayudarán a detallar objetivamente el presente trabajo y son: cualitativo, deductivo, inductivo y bibliográfico.

En el método cualitativo se utilizará a partir de la caracterización del sistema jurídico ecuatoriano y sus variables, determinación de creencias, así como del nivel de aceptación de los sistemas, procedimientos y comportamientos asumidos en la prevención y sanción eficaz en la utilización indebida de información privilegiada objeto de estudio, su correspondencia con el sistema jurídico ecuatoriano y con los aspectos relacionados al mercado de valores.

En el método deductivo, se aplicará como un procedimiento lógico de razonamiento deductivo, donde se analiza y se procesa la información para deducir las regularidades y determinar las 
carencias en el sistema jurídico ecuatoriano ante las condiciones actuales del sistema jurídico ecuatoriano para la prevención y sanción eficaz en la utilización indebida de información privilegiada de los mercados de valores.

En el método inductivo, que va de lo particular a lo general y que contribuye en la investigación constituyéndose en el referente para organizar la teoría y la información que sirve de sustento a la misma.

En el método bibliográfico, se utilizará con el propósito de conocer, ampliar, profundizar y deducir nuevos y diferentes enfoques, teorías, conceptos y criterios de diferentes autores sobre el sistema jurídico ecuatoriano, sus variables, y relaciones, así como indicadores de desempeño a nivel del sistema jurídico ecuatoriano para la prevención y sanción eficaz en la utilización indebida de información privilegiada de los mercados de valores.

El impacto del progreso del sistema jurídico ecuatoriano, está representado en el estudio de acuerdo al registro empresarial usada en la prevención y sanción eficaz en la utilización indebida de información privilegiada de los mercados de valores, disponiendo el examen y la correspondencia de modo más recóndito, los argumentos y prácticas que constituyen el presente trabajo.

\section{DISCUSIÓN}

El sistema jurídico ecuatoriano para la prevención y sanción eficaz en la utilización indebida de información privilegiada de los mercados de valores estimula mucha ventaja no solo por la categoría de las organizaciones implicadas; sino conjuntamente, por la confusa acción jurídica que encierra, pues crea gran disputa sobre el uso de la información privilegiada por los insider trading y su repercusión en la transparencia de las negociaciones en el mercado de valores ecuatoriano; la eficacia del insider trading dentro de nuestra legislación bursátil y el método de las pruebas indiciarias en la administración de igualdad administrativas.

Así mismo, se recubre especial importancia y consecuencias positivas por la confianza que debe generar en el inversionista, los que esperan del mercado de valores una elección de rentabilidad, es así que las normas regulatorias de la transparencia han determinado los parámetros que imprimen la vía transparente para permitir al control de las organizaciones.

La figura del uso indebido de la información privilegiada por insider trading, espera que las ganancias puedan repartirse $o$ fragmentarse entre varios sujetos que, procediendo expresamente en nombre propio y de manera autónoma, maniobren en el contexto bajo una 
idéntica causa o unidad de propósito con el fin de lograr o fortalecer la intervención de la sociedad afectada. Ello involucra que el uso indebido de la información privilegiada por insider trading, no puede relacionarse sin más a cualquier tipo de acuerdo o elaboración entre distintas personas que logren de forma sincrónica operaciones de una sociedad apreciada, ni a la simple cercanía temporal de sus concernientes negocios de adquisición, pues la misma solo puede ser estimada en los aparente en que dichas personas hagan uso indebido de esta información privilegiada necesariamente para lograr una participación accionarial significativa.

La particularidad de la transparencia en el mercado de valores ecuatoriano, que esencialmente es un texto de valores: el respeto a la legalidad y las organizaciones fundamentales del mercado de valores, que en el presente trabajo se fundamenta en que el uso indebido de la información privilegiada por los insider trading, tiene incidencia en la transparencia de las negociaciones en el mercado de valores ecuatoriano.

La destreza de acción establecida y del uso indebido de la información privilegiada por el insider trading (causa simulandi) realizada por los casos presentados, es para adquirir el control de directorios de empresas, la comprometida aplicación del Principio de Transparencia en el mercado de valores ecuatoriano, del cual proceden las necesidades de transparencia en el uso adecuado de la información privilegiada por parte del insiders tradings, lo que contiene la obligación de dejar ver planes futuros, endeudamientos, etc.

Secundariamente se hubiesen creado: Un mayor costo de la operación; La distribución de la prima de control entre todos los accionistas de empresas y La posibilidad de que cualquier otro tercero.

Quien deliberadamente decide incumplir la ley y es consciente de sus consecuencias, va a procurar ocultar todo rasgo que lo delate. Nadie planea infringir una norma, sin previamente valorar y meditar la manera de evadir la sanción. Así quien simula un negocio jurídico, va a pretender justificar su apariencia y racionalidad y, de paso, ocultar toda información que pudiera estar relacionada con el negocio oculto.

De la misma manera, si dos personas deciden adquirir haciendo uso indebido de la información privilegiada, el control de una empresa, como lo exige la legislación del mercado de valores, es natural que realicen todos los actos que estén a su alcance para que el uso indebido de la información privilegiada no sea detectada. 
Esta actividad incluirá la celebración de pactos informales en lugar de acuerdos escritos, la eliminación de toda documentación relacionada con los objetivos planeados y la apelación a diversos argumentos que justifiquen una supuesta actuación independiente. Tan antiguo como la ley, es el deseo de evadir sus alcances.

La pericia del insider trading en el ocultamiento de un acto ilegal. No garantiza, sin embargo, el éxito de una empresa. Tan ancestral como las conductas simuladas o uso indebido de información privilegiada, es la creación por parte de la legislación, la jurisprudencia y la doctrina, de mecanismos jurídicos que las detecten y sancionen a pesar de las dificultades.

\section{CONCLUSIONES}

El tamaño del mercado ecuatoriano de valores es pequeño en relación a la economía en conjunto. Es un sector poco característico para la economía íntegramente a la deficiente participación empresarial y de inversionistas en el sector. La legislación bursátil ecuatoriana instituye en sus prácticas el uso indebido de información privilegiada, como una contravención administrativa, y el comprometido será digno a una sanción administrativa; en relación a la reforma de LMV, dándose mayor categoría a esta imagen y su infracción corresponderían considerársela como un delito de defraudaciones. Los delitos informáticos son conductas criminógenas enfocadas a la destrucción de los bienes jurídicos protegidos, manejado como instrumento principal a las tecnologías de la información y comunicación.

En el Ecuador, con la expedición del Código Orgánico Integral Penal, la normativa referente a los delitos informáticos ha prosperado medianamente, sin embargo, dada la naturaleza de los ciberdelitos, se deriva a que éstos demandan acciones sincronizadas, sistematizadas y complementarias en el país y en la región, con el fin de reducir el impacto negativo de los ciberdelitos en la ciudadanía.

Los delitos informáticos al ser por su propia naturaleza diferentes a los delitos comunes, demandan sin duda alguna un procedimiento especial y determinado en la persecución que el Estado Ecuatoriano realiza. Es decir, al ser la aplicación del tipo penal novedosa en la mayoría de estos ilícitos, se requiere de un mayor esfuerzo técnico en la investigación, que permita instituir la correspondiente sanción al sujeto activo.

En el Ecuador, resulta casi imposible comprobar la relación que guarda el infractor con el delito, concretamente por el hecho de que el juez designado a administrar justicia, no posee una idea concreta de las características y elementos que debe reunir el delito informático para ser 
catalogado como tal, de ahí entonces que se llegue al equívoco de equiparar los delitos, por el que se insiste que su tratamiento debe ser rigurosamente

Del concepto de información privilegiada, es la determinación de la Corte de que la "intención" de un agente de mercado igualmente puede llegar a considerar como información privilegiada, si tiene el potencial de afectar la cotización de un valor en el mercado, por lo que la información privilegiada no tiene por qué constar por escrito; y en el caso concreto que se analizó, tal propósito si tenía esa potencialidad. Si la información que un accionista traspasa a otro tiene ese potencial, es por consiguiente información privilegiada.

La LMV suministra a cada uno de los agentes que en él proceden de los medios para vigilar porque sus fallos de inversión o desinversión se adopten con plena autonomía e independencia, sin que ellas se vean afectadas, determinadas o "contaminadas" por informaciones proporcionadas por sus competidores con la intención de inhabilitarlos en la disputa para remontar perspectivas negociadoras; que entre estas opciones, en primer lugar, está la que consiente al receptor de la información miembros del pacto de control del banco evaluar si quien la suministra tiene o no la capacidad económica para plasmarla o concretarla, pues de ello estribará su aptitud para afectar la cotización del valor en el mercado, y que permite diferenciarla de un simple rumor.

Se analiza el uso indebido de la información privilegiada por los insider trading en el mercado de valores ecuatoriano se manifiesta que este uso es indebido, cuando no se respeta la Ley del mercado de valores y más aun no existe un efectivo reglamento de sanciones, lo cual tiene incidencia en la transparencia de las negociaciones en el mercado de valores ecuatoriano.

Se describe la transparencia de las negociaciones en el Mercado de Valores ecuatoriano y esta tiene las siguientes características: La participación de inversionistas institucionales nacionales y extranjeros, con un manejo más completo y elaborado de inversiones han generado nuevas exigencias de información, encaminando hacia estándares existentes en otros mercados; y la Influencia de otros mercados a través de las experiencias exitosas de empresas nacionales que han ingresado a ellos (producto de la globalización), originando la necesidad de estas de adecuarse a prácticas más transparentes.

\section{REFERENCIAS BIBLIOGRÁFICAS}

1969., D. E. (s.f.). "El Diagnostico del Mercado de Valores en el Ecuador”. Publicado en R.O No. 216, de 7 de julio de 1969.Citado por la Superintendencia de Compañías del Ecuador. 
1969., D. -L. (1969). “El Diagnostico del Mercado de Valores en el Ecuador”. Publicado en el R.O. No. 144 de 26 de marzo de 1969.Citado por la Superintendencia de Compañías del Ecuador.

Córdova, M. (2015). Mercado de Valores. . Colombia: Ecoe .

Court Monteverde, E. y. (2010). Mercado de capitales (1era ed.). Naucalpan de Juárez: Pearson Educación. .

Ecuador, E. M. (1984 ). Quito - Ecuador.: Superintendencia de Compañías. .

Garzón Viteri, A. (2008). El Mercado de Valores y los Derivados Financieros. Su Enfoque Jurídico. (Tesina de Grado). Quito: Pontificia Universidad Católica del Ecuador. , pag 5.

Garzón Viteri, A. (2008). El Mercado de Valores y los Derivados Financieros. Su Enfoque Jurídico. (Tesina de Grado). Quito: Pontificia Universidad Católica del Ecuador. , pag 4.

Hablich Sánchez , F., Taola Rocuano, I., \& Agila Maldonado, M. (2018). Las empresas públicas con economía mixta en el mercado de valores en el Ecuador. Revista Científica Mundo de la Investigación y el Conocimiento. Vol. 2 núm., 1, 784-799.

Hartman, L. D. (2014). Business Ethics: Decision Making for Personal Integrity and Social Responsibility. Chicago, United States of America. McGraw-Hill.

LAROUSSE, (. D.-e. (s.f.). LAROUSSE, (s/a) Diccionario ingles español. (s.f.). Recuperado de http://www.larousse.com/es/diccionarios/ingles-espanol/insider/19144.

Méndez Prado, S. (2016). Mercado de valores ecuatoriano, sus limitantes de desarrollo 2015. Revista ESPOL Economía, 117-1-554-1-10-20160728, 1-5.

Peru., S. d. (2014). semanaeconomica.com. Obtenido de semanaeconomica.com.: http://semanaeconomica.com.

Press, O. U. (2003). Gran Diccionario Oxford. . (3ra ed.). (CD-ROM).

Rumazo Arcos, J. (1990). El Diagnostico del Mercado de Valores en el Ecuador. El "Securities Act" de 1933 y el "Securities Exchange Act" de 1934. (s.f.). Las importantes normas que regulan los Valores. 
Salazar, H. ( 2014). La Lesion de los derechos de los accionistas en el Peru como efecto generado por la conducta indebida del insider trading en la apliacion de la politica economica. La Lesion de los derechos de los accionistas en el Peru como efecto generado por la conduct.

Torres, J. (2002). Emisión de Obligaciones en el Régimen Legal del Perú. Lima: Editorial Cultural Cusco. .

Vega, J. R. (2010). El delito de uso de Información Privilegiada en el Mercado de Valores, Especialmente en el Derecho Penal Español (Art. 285 CP). . Universidad de Alcalá, Alcalá de Enares, España. 